\title{
Cytomegalovirus in bronchoalveolar lavage specimens from patients with AIDS: comparison with antigenaemia and viraemia
}

\author{
ELENA ANGELICI, C. CONTINI†, GABRIELLA SEBASTIANI*, F. FOLGORI*, S. DELIA*, P. SERRA \\ and MARIA SIPONTINA MAGNO* \\ Dipartimento Medicina Clinica and *Dipartimento Malattie Infettive, Università di Roma 'La Sapienza' and \\ †/stituto Malattie Infettive e Respiratorie, Università di Ferrara, Italy
}

\begin{abstract}
Pulmonary infection with cytomegalovirus (CMV) is a well recognised complication of AIDS. It is often possible to detect CMV-infected cells in bronchoalveolar lavage (BAL) specimens with monoclonal antibodies, but the clinical significance of their presence remains unclear. To investigate this, 24 AIDS patients were tested for CMV antigenaemia and viraemia, in addition to CMV detection in BAL. CMV was detected in the BAL of nine patients $(38 \%)$, five with clinical and laboratory evidence of pulmonary infection and four without pulmonary involvement. Blood samples positive for CMV antigen were observed in two patients with CMV-positive BAL specimens and, in both cases, antigenaemia resolved without therapy. No case of viraemia was detected. Pneumocystis carinii was detected concomitantly with CMV in the BAL of four of the patients with pulmonary involvement and in one without signs of pulmonary infection. These data suggest that CMV-positive BAL results are of limited significance in the diagnosis of CMV pneumonia in AIDS patients, unless associated with high levels of antigenaemia or viraemia and compatible clinical symptoms.
\end{abstract}

\section{Introduction}

In AIDS patients, pulmonary infection with cytomegalovirus (CMV) is a well recognised complication. Bronchoalveolar lavage (BAL) has proved to be a safe, well tolerated and useful procedure for establishing the aetiology of opportunist pulmonary infections. Some authors have suggested that immunofluorescence of BAL specimens with CMV-specific monoclonal antibodies (MAbs) can be used to distinguish CMV pneumonitis from asymptomatic viral shedding [1]. Others have not been able to confirm this view [2,3] and some groups have shown that the presence of CMV in the lungs is not necessarily associated with a poor clinical outcome [4-6].

Previous studies $[4,7,8]$, have demonstrated a high (44\%) incidence of CMV-infected cells in BAL specimens from AIDS patients with and without signs of pulmonary infection, both in the presence and absence of other associated pathogens. This suggests that the detection of $\mathrm{CMV}$ in BAL specimens is of

Received 10 Aug. 1995; revised version accepted 28 Dec. 1995.

Corresponding author: Dr E. Angelici, II Pat. Medica (VI Clinica Medica), Viale del Policlinico 155, 00161 Rome, Italy. questionable clinical significance. In contrast, the demonstration of CMV in blood samples is particularly important because CMV viraemia is considered to be a marker of active infection and it has been shown to correlate well with significant CMV disease [9].

Recently, an antigen test has been described as a sensitive and rapid method for the detection of CMV in peripheral blood leucocytes (PMNLs) [10-12]. Higher numbers of CMV antigen-positive leucocytes have been shown to correlate with viraemia and clinical symptoms. However, as CMV can be present in the respiratory tract of asymptomatic patients as well as a cause of active and invasive disease, it is essential that a rapid test for the diagnosis of CMV pneumonia should be both sensitive and specific for significant clinical disease. The purpose of the present study was to evaluate the usefulness of detecting of CMV antigenaemia and viraemia in determining the clinical significance of $\mathrm{CMV}$ in BAL specimens from AIDS patients.

\section{Materials and methods}

Twenty-four AIDS patients were divided into two groups. Group I comprised 15 patients with clinical 
and laboratory evidence of pulmonary infection and group II comprised nine patients without pulmonary involvement. Group II included one patient with a cough which was considered to be due to bronchial hyper-reactivity. The clinical characteristics of these patients are summarised in Table 1. All patients were evaluated by clinical examination, chest X-ray, arterial blood gases and BAL. Venous blood specimens were collected in two EDTA-treated tubes for isolation of CMV.

A standard procedure was followed for the BAL [13]. The involved lobe (when pathology was visible) or the lingula (when chest X-ray was normal), was washed with $50 \mathrm{ml}$ of normal saline solution pre-warmed to $37^{\circ} \mathrm{C}$ and the fluid was then aspirated into a calibrated sterile container; this process was repeated three times. Bacteriological investigations performed on BAL included Gram's stain, Ziehl-Neelsen stain and cultures for conventional bacteria, mycobacteria and fungi. Immunofluorescence and Grocott's methenamine silver stain were used to detect Pneumocystis carinii [14]. Toxoplasma gondii investigation was performed by immunofluorescence (IF) with an anti-P-30 $T$. gondii $\mathrm{MAb}$ and fluorescein-labelled anti-mouse IgG conjugate (Pasteur Diagnostics, France) [15]. For culture of viruses other than CMV, $0.3 \mathrm{ml}$ of BAL fluid was inoculated into each of two cell lines: Vero monkey kidney and human epithelial cells (HEp-2) [16].

\section{$C M V$ detection in $B A L$}

Shell vial cell cultures (SVCC) were performed with human fibroblasts (HELF) seeded on shell vials and maintained with minimal essential medium (MEM) containing fetal calf serum (FCS) $10 \%$ in a humidified atmosphere containing $\mathrm{CO}_{2} 5 \%$. Before inoculation, MEM was removed and $100 \mu \mathrm{l}$ of the BAL cell suspension were added to each vial; MEM containing FCS $2 \%$ was replaced in each shell vial and cultures were incubated at $37^{\circ} \mathrm{C}$.

Titrated virus stock (HCMVAD 169) was diluted in MEM to a concentration of c. 20 infective particles/ inoculum and used as a positive control. MEM alone was used as the negative control.
After incubation for $24 \mathrm{~h}$, the medium was removed and the coverslips with infected cells were fixed with acetone for $10 \mathrm{~min}$ at $-20^{\circ} \mathrm{C}$ and stained with optimal dilutions of anti-CMV early nuclear protein $72-\mathrm{kDa}$ (Du Pont) and then with the fluorescein-conjugated goat anti-mouse antibodies. Mounted coverslips were examined immediately with an incident-light fluorescence microscope (Zeiss) and the number of typically fluorescing nuclei was recorded.

\section{CMV antigenaemia assay}

Polymorphonuclear leucocytes (PMNLs) were isolated from $3 \mathrm{ml}$ of EDTA-treated venous blood by dextran sedimentation. The CMV detection procedure of van der $\mathrm{Bij}$ et al. [10], as modified by Revello et al. [11], was followed. The viral protein identified was the lower matrix phosphoprotein PP65 [12]. Positively stained leucocytes showed homogeneous yellow-green nuclear staining by immunofluorescence (IF). Results were expressed quantitatively as the number of CMV antigen (Ag)-positive cells/200 000 cells examined. A result of $<10$ was considered a low positive, $10-49$ as an intermediate positive and $>50$ as a strong positive result.

\section{CMV culture}

PMNLs were isolated from $3 \mathrm{ml}$ of EDTA-treated venous blood by dextran sedimentation. For CMV culture, human fibroblast monolayers seeded in shell vials were inoculated with $0.3 \mathrm{ml}$ of leucocyte suspension and centrifuged at $700 \mathrm{~g}$ for $45 \mathrm{~min}$. Monolayers were washed and MEM containing FCS $2 \%$ was replaced. After incubation for $24 \mathrm{~h}$, monolayers were examined and then fixed in acetone and stained with $\mathrm{MAb}$ as described above for BAL cell cultures.

\section{Results}

CMV was detected in the BAL of nine $(38 \%)$ of the 24 AIDS patients, five from group I and four from group II (Table 2). In six instances, CMV was associated with other micro-organisms, namely $P$. carinii (5) and Herpes simplex virus (1). $P$. carinii was detected in five of the nine CMV-positive BAL specimens (55\%),

Table 1. Clinical and laboratory characteristics of the two patient groups

\begin{tabular}{lcc}
\hline Characteristic & $\begin{array}{c}\text { Group I } \\
(\mathrm{n}=15)\end{array}$ & $\begin{array}{c}\text { Group II } \\
(\mathrm{n}=9)\end{array}$ \\
\hline Median age (range) & $32(26-38)$ & $34(26-54)$ \\
$\mathrm{Sex}$ & 14 male; 1 female & 8 male; 1 female \\
$\begin{array}{l}\text { Median CD4 cell counts } / \mathrm{mm}^{3} \\
\quad \text { (range) }\end{array}$ & $23(2-100)$ & $25(4-88)$ \\
$\begin{array}{c}\text { Chest X-ray evidence of } \\
\text { respiratory disease }\end{array}$ & 15 & 0 \\
$\mathrm{pO}_{2}<85$ mmHg & & 0 \\
$\quad$ median (range) & 8 & $86(85-104)$ \\
Acute respiratory symptoms & $82(56-98)$ & 1 \\
\hline
\end{tabular}


Table 2. Individual results of BAL, antigenaemia and viraemia assays for all patients

\begin{tabular}{|c|c|c|c|c|c|c|c|c|c|}
\hline \multicolumn{5}{|c|}{ Group 1} & \multicolumn{5}{|c|}{ Group II } \\
\hline \multirow{2}{*}{$\begin{array}{l}\text { Patient } \\
\text { no. }\end{array}$} & \multicolumn{3}{|c|}{ CMV assay results for } & \multirow{2}{*}{$\begin{array}{l}\text { Other BAL } \\
\text { pathogens }\end{array}$} & \multirow{2}{*}{$\begin{array}{c}\text { Patient } \\
\text { no. }\end{array}$} & \multicolumn{3}{|c|}{ CMV assay results for } & \multirow{2}{*}{$\begin{array}{l}\text { Other BAL } \\
\text { pathogens }\end{array}$} \\
\hline & BAL & antigenaemia & viraemia & & & BAL & antigenaemia & viraemia & \\
\hline 1 & + & - & - & $\begin{array}{l}\text { Herpes simplex } \\
\text { virus }\end{array}$ & 1 & - & - & - & $\ldots$ \\
\hline 2 & - & - & - & P. carinii & 2 & - & - & - & $\ldots$ \\
\hline 3 & - & - & - & $\ldots$ & 3 & - & - & - & $\ldots$ \\
\hline 4 & - & - & - & $P$ carinii & 4 & - & - & - & $\ldots$ \\
\hline 5 & + & - & - & P. carinii & 5 & + & - & - & P. carinii \\
\hline 6 & + & - & - & P. carinii & 6 & + & - & - & $\ldots$ \\
\hline 7 & - & - & - & T. gondii & 7 & - & - & - & $\ldots$ \\
\hline 8 & + & $+(50)^{*}$ & - & P. carinii & 8 & + & - & - & $\ldots$ \\
\hline 9 & - & - & - & Ps. aeruginosa & 9 & + & - & - & $\ldots$ \\
\hline 10 & - & - & - & $P$ carinii & & & & & \\
\hline 11 & - & - & - & P. carinii & & & & & \\
\hline 12 & - & - & - & P. carinii & & & & & \\
\hline 13 & + & $+(2)^{*}$ & - & P. carinii & & & & & \\
\hline 14 & - & - & - & & & & & & \\
\hline 15 & - & - & - & P. carinii & & & & & \\
\hline
\end{tabular}

${ }^{*}$ Number of positive cells.

four from group I and one from group II. All patients received therapy with trimethoprim and sulphamethoxazole but antiviral therapy was not administered to any patient and all recovered promptly. In three patients in group II, CMV was the only agent detected and these patients recovered within 4 weeks without anti-CMV treatment.

In group I, the five patients with CMV-positive BAL were not different from the remaining 10 patients with regard to their clinical state, CD4 cell counts (median values 36 and $25 / \mathrm{mm}^{3}$, respectively), or therapy received. A relatively high incidence (4 of 9) of positive CMV results was observed in BAL specimens from patients in group II. In two cases CMV was the only pathogen detected, while a third patient with previous CMV retinitis was being treated with a specific antiviral agent. In the last instance, CMV was detected together with $P$. carinii. Low (two positive cells) and high (50 positive cells) levels of antigenaemia were observed in two patients from group I, both with positive BAL. In both cases antigenaemia resolved without therapy. Positive viraemia was not detected in any of the 24 patients. Other microorganisms isolated in or detected from BAL specimens were T. gondii (1) and Pseudomonas aeruginosa (1).

\section{Discussion}

The present study demonstrated a high incidence of CMV in BAL specimens from patients with AIDS, a finding previously reported by several investigators $[4$, $8,17]$. In more than half of these instances $(55 \%), P$. carinii was detected concomitantly and all patients responded well to specific therapy for the latter organism. Antigenaemia and viraemia, which are supposedly sensitive and specific indicators of diagnosis of CMV infection, were found to be useful only because of their negativity. This suggests that positive CMV results in BAL specimens lack clinical significance.

We believe that a positive CMV result in a BAL has no meaning for two reasons. Firstly, in all patients, the acute symptomatology showed clinical improvement without any antiviral treatment. Secondly, and perhaps of greater importance, BAL specimens positive for CMV were observed in four of the nine patients in group II. In one of these patients CMV detection was associated with $P$. carinii. This patient was still included in group II because of the absence of clinical or radiological evidence of pulmonary involvement. As described by other authors [18], P. carinii can be isolated from asymptomatic patients, whether HIV positive or negative, due to persistence of the organism after previous infection, or to the presence of non-pathogenic strains.

There was no difference in group I between patients with positive BAL and patients with negative BAL results insofar as the level of immunosuppression was concerned. All were severely immunodepressed as documented by a low CD4 cell count. In group II, represented by patients without clinical or laboratory evidence of respiratory disease, the isolation of CMV by BAL was not considered an index of active disease. This study found, as others have $[3,4]$, a relatively high incidence $(44 \%)$ of CMV positivity in BAL specimens from such patients. This observation lends support to the view that in AIDS patients, CMV detection in BAL has no clinical relevance. Griffiths [19] has suggested that in AIDS patients detection of $\mathrm{CMV}$ in the lung does not require specific therapy. The results of this study, in agreement with Millar et al. $[17,18]$, provide no evidence that CMV caused pneumonitis, despite the presence of CMV in the lungs. 
Gerna et al. [20], correlated levels of antigenaemia with clinical symptoms, and observed that in AIDS patients the correlation between symptoms and CMV infection is more difficult because of the co-existence of other pathogens. However, clinical symptoms are often present when antigenaemia levels are high $(>80)$. Similarly, Landry and Ferguson [21] believe that, with a few exceptions, clinical disease is associated with high antigen levels in blood, whereas low levels of antigen are usually observed in asymptomatic individuals. Mazzulli et al. [22] evaluated antigenaemia in 36 patients with AIDS. In that study, there was only one patient with pneumonia, a questionable diagnosis based solely on one antigenpositive specimen for CMV in leucocytes, one positive blood culture and one positive BAL. No clinical data were given.

In two of the patients in the present study, BAL specimens positive for CMV were associated with low and high levels of antigenaemia, respectively. Subsequent blood samples obtained 1 month later revealed no CMV-antigen-positive PMNLs. This is further evidence that positive CMV results from BAL specimens are of limited significance in the diagnosis of respiratory infections unless associated with high antigenaemia levels, viraemia and clinical symptoms. In two patient, antigenaemia became negative without therapy. Other authors have reported that, even in the presence of high levels of viraemia, the virus can be cleared from blood spontaneously in the absence of any therapy [20].

The results of the present study are not surprising, as CMV infection is nearly universal in homosexual men with AIDS. Nearly $100 \%$ of homosexual men with AIDS are seropositive for CMV [23], and 30-40\% have CMV in their semen or urine [24], presumably due to reactivation secondary to the immunodepressed state.

In conclusion, we agree with Woods et al. [25], who recommend that the presence or absence of $\mathrm{CMV}$ pneumonia should be confirmed by biopsy, even though the presence of histologic changes suggestive of CMV in lung biopsies from AIDS patients does not establish that this virus is the cause of pneumonitis [18]. In patients with probable CMV pneumonia, the diagnosis is acceptable only if the following criteria are satisfied: (1) compatible clinical and radiological data; (2) failure to recover a pathogen other than CMV from respiratory specimens and perhaps (3) high antigenaemia and viraemia.

\section{References}

1. Emanuel D, Peppard J, Stover D, Gold J, Amstrong D, Hammerling U. Rapid immunodiagnosis of cytomegalovirus pneumonia by bronchoalveolar lavage using human and murine monclonal antibodies. Ann Int Med 1986: 104: 476-481.
2. Volin L, Leskinen $\mathrm{R}$, Taskinen $\mathrm{E}$ et al. Bronchoalveolarlavage in the diagnosis of pulmonary complications in bone marrow transplant recipients. Transplant Proc 1986; 18: 130-131.

3. Ruuto P, Ruutu T, Volin L, Tukiainem P, Ukkonen P, Houi T. Cytomegalovirus is frequently isolated in bronchoalveolar lavage fluid of bone marrow transplant recipients without pneumonia. Ann Int Med 1990; 112: 913-916.

4. Miles PR, Baughman RP, Linnemann CC. Cytomegalovirus in the bronchoalveolar lavage fluid of patients with AIDS. Chest 1990; 97: 1072-1076.

5. Glaser JH, Schuval S, Burstein O, Bye MR. Cytomegalovirus and Pneumocystic carinii pneumonia in children with acquired immunodeficiency syndrome. J Pediatr 1992; 120: 929-931.

6. Brodie HR, Broaddus C, Hopewell PC, Moss A, Mills J. Is Cytomegalovirus (CMV) a cause of lung disease in patients with AIDS? Am Rev Respir Dis 1985; 131 Suppl: A227.

7. Angelici E, Magno MS, Forte S, Del Monaco F, Serra P, De Rosa F. Rapid detection of Cytomegalovirus in bronchoalveolar lavage in AIDS patients: its possible clinical significance. Ther Infect Dis 1991; 3: 357-362.

8. Saltzman RL, Jordan MC. Cytomegalovirus infections. Curr Opin Infec Dis 1989; 2: 262-266.

9. Gadler J, Tillegård A, Groth C-G. Studies of cytomegalovirus infection in renal allograft recipients. I. Virus isolation. Scand $J$ Infect Dis 1982; 14: 81-87.

10. van der Bij W, Schirm J, Torensman R, van Sonu WJ, Tegzess $\mathrm{AM}$, The TH. Comparison between viremia and antigenemia for detection of Cytomegalovirus in blood. $J$ Clin Microbiol 1988; 26: 2531-2535.

11. Revello MG, Zavattoni M, Percivalle E, Grossi P, Gerna P. Correlation between immunofluorescent detection of human cytomegalovirus immediate early antigens in polymorphonuclear leukocytes and viremia. J Infect Dis 1989; 160: 159160.

12. Revello MG, Percivalle E, Di Matteo A, Morini F, Gerna G. Nuclear expression of the lower matrix protein of human cytomegalovirus in peripheral blood leucocytes of immunocompromised viremic patients. J Gen Virol 1992; 73: 437-442.

13. Reynolds HY. Brochoalveolar lavage. Am Rev Respir Dis 1987; 135: $250-263$.

14. Nato F, Contini C, Zamora-Zamala $\mathrm{C}$ et al. Production and characterization of monoclonal antibodies to human Pneumocystis carinii for the diagnosis of $P$. carinii pneumonia. Eur $J$ Med 1992; 1: 132-138.

15. Derouin F, Mazeron MC, Gariny JF. Comparative study of tissue culture and mouse inoculation methods for demonstration of Toxoplasma gondii. J Clin Microbiol 1994; 25: 15971600 .

16. Connolly MG, Baughman RP, Dohn MN, Linnemann CC, Recovery of viruses other than cytomegalovirus from bronchoalveolar lavage fluid Chest 1994; 105: 1775-1781.

17. Millar AB, Patou G, Miller RF et al. Cytomegalovirus in the lungs of patients with AIDS. Respiratory pathogen or passenger? Am Rev Respir Dis 1990; 141: 1474-1477.

18. Contini C, Romani R, Vullo V, Delia S, Sorice F. Does laboratory recovery of Pneumocystis carinii always mean clinically significant disease? AIDS 1992; 162: 1558-1559.

19. Griffiths PD. Current management of cytomegalovirus disease. J Med Virol 1993; 1 Suppl: 106-111.

20. Gerna G, Revello MG, Percivalle E, Zavottoni M, Parea M, Battaglia M. Quantification of human cytomegalovirus viremia by using monoclonal antibodies to different viral proteins. $J$ Clin Microbiol 1990; 28: 2681-2688.

21. Landry ML, Ferguson D. Comparison of quantitative Cytomegalovirus antigenemia assay with culture methods and correlation with clinical disease. J Clin Microbiol 1993; 31: 2851-2856.

22. Mazzulli T, Rubin R, Ferraro MJ et al. Cytomegalovirus antigenemia. Clinical correlations in transplant recipients and in persons with AIDS. J Clin Microbiol 1993; 31: 2824-2827.

23. Drew WL. Cytomegalovirus infection in patients with AIDS. $J$ Infect Dis 1988; 158: 449-456.

24. Collier AC, Meyers JD, Corey L, Murphy VL, Roberts PL, Handsfield HH. Cytomegalovirus infection in homosexual men. Relationship to sexual practices, antibody to human immunodeficiency virus, and cell-mediated immunity. Am J Med 1987; 82: $593-601$.

25. Woods GL, Thompson AB, Rennard SL, Linder J. Detection of Cytomegalovirus in bronchoalveolar lavage specimens. Chest 1990; 98: 568-575. 